\title{
Crescimento do tomateiro cultivado em solo coberto com polipropileno preto $^{1}$
}

\author{
Growth of tomato plants grown in soil covered with black polypropylene
}

\author{
Alinne Menezes Soares ${ }^{2 *}$, Maria Zuleide de Negreiros², Welder de Araújo Rangel Lopes ${ }^{2}$, Jeferson Luiz \\ Dallabona Dombroski ${ }^{2}$ e Rafaella Rayane Macedo de Lucena ${ }^{2}$
}

\begin{abstract}
RESUMO - Realizou-se um experimento para avaliar o crescimento e partição de assimilados de plantas de tomate cultivadas sob cobertura ou não do solo com polipropileno preto. O delineamento experimental foi em blocos casualizados completos, com parcelas subdivididas e quatro repetições. Nas parcelas, os tratamentos se constituíram de dois sistemas de cultivo (com e sem cobertura do solo polipropileno preto, TNT) e nas subparcelas, as épocas de amostragem das plantas: $14 ; 28 ; 42 ; 56 ; 70 ; 84 ; 98$ e 112 dias após o transplantio, DAT. Foram avaliados: acúmulo de massa seca nas folhas (MSF), ramos (MSR), inflorescências (MSI), frutos (MSFR) e total (MST), área foliar (AF), razão de área foliar (RAF), taxa assimilatória líquida (TAL), taxa de crescimento absoluto (TCA) e taxa de crescimento relativo (TCR). A cobertura de solo não influenciou o MSF, MSR, MSI, MSFR e MST como também a AF, RAF, TAL, TCA e TCR. Os frutos se comportaram como dreno preferencial da planta, chegando ao final do ciclo com 47,77\% do total da massa seca acumulada. A AF, RAF e TCA atingiram valores máximos aos 83; 27 e 73 DAT, com médias de $75.835 \mathrm{~cm}^{2}$ planta $^{-1}, 201,5 \mathrm{~cm}^{2} \mathrm{~g}^{-1}$ e $14,87 \mathrm{~g} \mathrm{planta}^{-1}$ dia $^{-1}$, respectivamente, enquanto a TCR e a TAL decresceram durante todo o período de avaliação.
\end{abstract}

Palavras-chave: Lycopersicon esculentum Mill. Massa seca. Agrotêxtil.

\begin{abstract}
An experiment was carried out to evaluate the growth and division of treated tomato plants grown in soil covered or not with black polypropylene. The experimental design was of randomised complete blocks, in split plots and four replications. In the plots, the treatments consisted of two systems (with and without a black polypropylene TNT covering) and in the subplots, plant-sampling times of 14, 28, 42, 56, 70, 84, 98 and 112 days after transplanting (DAT). The following were evaluated: dry matter accumulation in the leaves (DML), the branches (DMB), the inflorescences (DMI), the fruits (DMFR) total dry mass (TDM), the leaf area (LA), leaf area ratio (LAR), net assimilation rate (NAR), absolute growth rate (AGR) and relative growth rate (RGR). The ground cover did not influence the DML, DMB, DMI DMFR or TDM as well as LA, LAR, NAR, AGR or RGR. The fruits behaved as preferential drain for the plant, reaching the end of the cycle with $47.77 \%$ of the total dry mass accumulation. The LA, LAR and AGR reached maximum values at 83, 27 and 73 DAT, averaging 75,835 $\mathrm{cm}^{2}$ plant $^{-1}, 201.5 \mathrm{~cm}^{2} \mathrm{~g}^{-1}$ and $14.87 \mathrm{~g} \mathrm{plant}^{-1}$ day $^{-1}$ respectively, while the RGR and NAR decreased throughout the evaluation period.
\end{abstract}

Key words: Lycopersicon esculentum Mill. Dry mass. Agrotextile.

\footnotetext{
*Autor para correspondência

'Recebido para publicação em 11/10/2011; aprovado em 18/02/2013

Parte da Monografia de conclusão do curso de graduação em Agronomia da primeira autora, pesquisa financiada com recursos do CNPq ${ }^{2}$ Departamento de Ciências Vegetais, Universidade Federal Rural do Semi-árido/UFERSA, Km 47, BR 110, Costa e Silva, Caixa Postal 137, Mossoró-RN, Brasil, 59.625-900, alinne_menezes@hotmail.com, zuleide@ufersa.edu.br, welder.lopes@hotmail.com, jeferson@ufersa.edu.br, rafaellarayane@hotmail.com
} 


\section{INTRODUÇÃO}

O tomate (Lycopersicon esculentum Mill.) é uma hortaliça de grande importância econômica, sendo hoje a segunda mais produzida no mundo. O Brasil está entre os 10 maiores produtores mundiais, com uma produção, em 2011, de 4.425.274 toneladas (INSTITUTO BRASILEIRO DE GEOGRAFIA E ESTATÍSTICA, 2012; ORGANIZAÇÃO DAS NAÇÕES UNIDAS PARA A AGRICULTURA E A ALIMENTAÇÃO, 2012). O cultivo do tomateiro está presente em diversas áreas agrícolas do país, destacando-se as regiões do Sudeste e CentroOeste. O Nordeste brasileiro apresenta ótimas condições para o cultivo de tomate, com destaque para os estados da Bahia, Pernambuco e Ceará, que contribuíram em 2010, com 55,50; 18,82 e 18,73\%, respectivamente, do total produzido na Região (INSTITUTO BRASILEIRO DE GEOGRAFIA E ESTATÍSTICA, 2012).

A busca por melhor ambiente para o cultivo de tomate tem sido o foco principal de alguns produtores do Rio Grande do Norte, havendo necessidade de pesquisa com a cultura no que diz respeito ao seu manejo, que inclui o estudo de práticas como o uso de cobertura do solo "mulching".

Os materiais mais utilizados são filmes plásticos de polietileno (PET), os quais têm levado ao incremento em crescimento e produtividade em várias hortaliças (CHAVES et al., 2004; MEDEIROS et al., 2006; MORAIS et al., 2008) incluindo o tomateiro (LAMONT JUNIOR, 1993), embora possam ser empregados materiais de origem vegetal como raspas de madeira, palha de carnaúba e palha de milho (QUEIROGA et al., 2002). Conforme os autores, esse aumento no crescimento e na produtividade é atribuído às modificações na temperatura do solo e do ar próximo à cobertura, balanço hídrico e disponibilidade de nutrientes.

Embora os filmes plásticos de polietileno sejam amplamente utilizados como "mulching" em diversas hortaliças, não se tem observado o mesmo com o tecido de polipropileno (TP), também conhecido por agrotêxtil ou tecido não-tecido (TNT). O tecido de polipropileno tem sido empregado como manta sobre as plantas de melão e melancia até o início da floração (DANTAS et al., 2009; MEDEIROS et al., 2007). Na cultura da alface o agrotêxtil preto foi eficiente no controle de plantas daninhas, promovendo melhor desenvolvimento e produção de plantas com maior massa fresca (REGHIN et al., 2002).

Do ponto de vista agronômico, a análise de crescimento pode ser útil no estudo do comportamento vegetal sob diferentes condições ambientais. A análise de crescimento é feita medindo-se a área foliar e as massas da matéria seca total e de partes (raízes, caules e frutos) da planta (KVET et al., 1971). Fontes, Dias e Silva (2005), estudando o crescimento de pimentão em ambiente protegido verificou que a produção de massa seca do fruto, caule, folhas, área foliar e taxa de absoluto aumentaram ao longo do tempo de cultivo.

A fim de fornecer subsídios para a exploração da cultura no estado, propõe-se nesse trabalho avaliar o crescimento e partição de assimilados pelo tomateiro cultivado em solo coberto com tecido polipropileno preto.

\section{MATERIAL E MÉTODOS}

O experimento foi conduzido no período de setembro de 2009 a janeiro de 2010, na Fazenda WG Fruticultura, localizada em Baraúna - RN, latitude 504'44" S, longitude 37³7'26" W e altitude de $94 \mathrm{~m}$, em Cambissolo Háplico de textura argilosa (EMPRESA BRASILEIRADEPESQUISAAGROPECUÁRIA, 1999). O delineamento experimental adotado foi o de blocos casualizados completos, com parcelas subdivididas e quatro repetições, sendo as parcelas representadas pelos tipos de cobertura de solo: sem cobertura do solo (testemunha) e com cobertura do solo com polipropileno preto (TNT) e as subparcelas pelas épocas de amostragem das plantas: $14 ; 28 ; 42 ; 56 ; 70 ; 84 ; 98$ e 112 dias após o transplantio (DAT). Cada parcela foi composta por três fileiras de plantas, considerando-se como área útil a fileira central, excluindo-se as plantas das extremidades.

O híbrido utilizado foi o 'SM-16' que apresenta plantas vigorosas de crescimento determinado, de bom pegamento de frutos, alta produtividade e com resistências à Verticillium albo-atrum e Verticillium dahliae (Raças 1 e 2), Meloidogyne incognita, Meloidogyne javanica e Meloidogyne arenaria e Fusarium com um ciclo médio de 115 a 120 dias (SEMINIS, 2011), sendo o mais cultivado pelos produtores da Região.

A semeadura foi realizada em 01/09/2009, em bandejas de poliestireno expandido de 200 células utilizando substrato comercial Golden $\mathrm{Mix}^{\circledR}$, à base de fibra de coco. As mudas foram transplantadas no estádio de 4 a 6 folhas definitivas para a área experimental, aos 25 dias após a semeadura, em espaçamento de 2,0 m entre fileiras e $0,50 \mathrm{~m}$ entre plantas.

Previamente ao transplantio foi realizado o preparo do solo através de aração e gradagem, seguido do sulcamento em linhas, espaçadas de $2,0 \mathrm{~m}$ com profundidade de $0,20 \mathrm{~m}$, onde foi realizada a adubação de plantio com $400 \mathrm{~kg} \mathrm{ha}^{-1}$ de fosfato monoamônico (MAP), com posterior fechamento dos sulcos e levantamento dos camalhões com $0,80 \mathrm{~m}$ de largura, distanciados entre eixos de 2,0 m, correspondentes à 
distância entre as fileiras de plantas. As adubações de cobertura foram efetuadas diariamente via fertirrigação, seguindo as recomendações da análise de solo, e obedecendo aos estádios de desenvolvimento da cultura, para tanto se utilizou $225 \mathrm{~kg} \mathrm{ha}^{-1}$ de $\mathrm{N}, 125 \mathrm{~kg} \mathrm{ha}^{-1}$ de $\mathrm{P}_{2} \mathrm{O}_{5}$ e $390 \mathrm{~kg} \mathrm{ha}^{-1}$ de $\mathrm{K}_{2} \mathrm{O}$.

O sistema de irrigação utilizado foi por gotejamento, constituído de um conjunto motobomba, com estação de controle composto de filtro de disco, sistema de controle de vazão e pressão e um injetor de fertilizante tipo Venturi, tubulações em PVC rígido de $50 \mathrm{~mm}$, linhas laterais de polietileno flexível de $16 \mathrm{~mm}$ e gotejadores com vazão de $1,5 \mathrm{~L} \mathrm{~h}^{-1}$, para uma pressão de serviço de $100 \mathrm{Kpa}$ e espaçados na linha de $0,30 \mathrm{~m}$. A quantidade de água necessária para irrigação foi estimada de acordo com a evapotranspiração da cultura (ALLEN et al., 1998). Este método leva em consideração a evapotranspiração de referência $\left(\mathrm{ET}_{0}\right)$ e o Kc para cada estádio de desenvolvimento.

Após a instalação do sistema de irrigação, o polipropileno preto com gramatura de $46 \mathrm{~g} \mathrm{~m}^{-2}$ foi colocado sobre os camalhões, correspondente às fileiras de plantas, nas parcelas dos tratamentos com cobertura do solo. A superfície coberta foi de $0,80 \mathrm{~m}$ de largura. As extremidades foram fixadas com o próprio solo dos camalhões. Posteriormente, efetuou-se a abertura dos orifícios de plantio, distanciados $0,50 \mathrm{~m}$, com um vazador de 2,5 polegadas de diâmetro e em seguida realizou-se o transplantio das mudas.

Para quantificar o crescimento, foram amostradas plantas de tomate em intervalos de quatorze dias, até os 112 dias após o transplantio (DAT). Após cada coleta, as plantas foram fracionadas em caules, folhas, inflorescências e frutos, em seguida foram lavadas e colocadas em estufa com circulação forçada de ar, à temperatura de $65^{\circ} \mathrm{C}$, até atingir massa constante. A área foliar foi estimada através do método do disco, que consistiu da retirada de discos, de área conhecida, das folhas frescas, através de um furador de rolhas. Com a obtenção da massa seca das folhas (MSF) e da massa seca dos discos (MSD) e a partir do conhecimento da área dos discos (AD), calculou-se a área foliar (AF) total através da equação:

$$
[\mathrm{AF}=(\mathrm{MSF} \mathrm{AD}) / \mathrm{MSD}]
$$

Seguindo as recomendações de Benincasa (2003), foram calculados: razão de área foliar - razão entre a área foliar (AF) e matéria seca total (MST)]; (Equação 2):

$$
[\mathrm{RAF}=(\mathrm{AF} / \mathrm{MST})]
$$

Taxa assimilatória líquida (Equação 3):

$\left[\mathrm{TAL}=\left[\left(\mathrm{P}_{2}-\mathrm{P}_{1}\right) /\left(\mathrm{T}_{2}-\mathrm{T}_{1}\right)\right] \cdot\left[\left(\ln \mathrm{A}_{2}-\ln \mathrm{A}_{1}\right) /\left(\mathrm{A}_{2}-\mathrm{A}_{1}\right)\right]\right.$

onde: $\mathrm{P}_{2}$ e $\mathrm{P}_{1}$ são as massas secas de duas amostragens,
$\mathrm{T}_{2}$ e $\mathrm{T}_{1}$ representam as épocas de amostragem e $\mathrm{A}_{2} \mathrm{e}$ $\mathrm{A}_{1}$ representaram as áreas foliares de duas amostragens sucessivas]; taxa de crescimento absoluto (Equação 4):

$\left[\mathrm{TCA}=\left(\mathrm{P}_{2}-\mathrm{P}_{1}\right) /\left(\mathrm{T}_{2}-\mathrm{T}_{1}\right)\right]$

onde $\mathrm{P}_{2}$ e $\mathrm{P}_{1}$ são as massas da matéria seca de duas amostragens sucessivas, e $T_{2}$ e $T_{1}$ representam as épocas de amostragem; e taxa de crescimento relativo (Equação 5):

$\left[\mathrm{TCR}=\left(\ln \mathrm{P}_{2}-\ln \mathrm{P}_{1}\right) /\left(\mathrm{T}_{2}-\mathrm{T}_{1}\right)\right]$

onde $\mathrm{P}_{2}$ e $\mathrm{P}_{1}$ são as massas secas de duas amostragens sucessivas, e $\mathrm{T}_{2}$ e $\mathrm{T}_{1}$ representam as épocas de amostragem.

Os dados foram submetidos às análises de variância através do software Sisvar ${ }^{\circledR}$ (FERREIRA, 2000), e de regressão não-linear (logística) (YIN et al., 2003), utilizando-se o software SPSS 15, e para as características que não se ajustaram ao modelo logístico, foram realizadas análises de regressão através do software Table Curve 2D v5.01 (JANDEL SCIENTIFIC, 1991).

\section{RESULTADOS E DISCUSSÃO}

Não foi verificado efeito significativo da interação Cobertura do solo (C) x Épocas de amostragem (E) para quaisquer das características avaliadas (Tabela 1 e 2). Os diferentes tipos de cobertura de solo não influenciaram significativamente a massa seca de folhas (MSF), ramos (MSR), inflorescências (MSI), frutos (MSFR) e total (MST), bem como área foliar (AF), razão de área foliar (RAF), taxa assimilatória líquida (TAL), taxa de crescimento absoluto (TCA) e taxa de crescimento relativo (TCR) ao longo do ciclo de tomate 'SM-16'. As médias gerais para tais características foram de 148,80 $\mathrm{g} \mathrm{planta}^{-1}, 75,04 \mathrm{~g}$

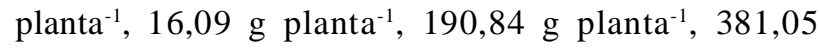
g planta ${ }^{-1}, 41404,12 \mathrm{~cm}^{2}$ planta $^{-1}, 145,82 \mathrm{~cm}^{2} \mathrm{~g}^{-1}$, $0,000413 \mathrm{~g} \mathrm{~cm}^{-2} \mathrm{dia}^{-1}, 5,89 \mathrm{~g}$ planta ${ }^{-1} \mathrm{dia}^{-1}, 0,0776 \mathrm{~g}$ $\mathrm{g}^{-1} \mathrm{dia}^{-1}$, respectivamente (Tabela 3 e 4 ).

O acúmulo de massa seca apresentou comportamento semelhante nas diferentes partes da planta. Nas folhas e nos ramos verificou-se que houve um crescimento lento até aproximadamente 28 dias, intensificando-se a partir desse período e obtendo seus valores máximos aos 85 e 94 dias após o transplantio (DAT), respectivamente, com médias de 279,40 e 133,17 g planta $^{-1}$ (Figura 1 ). Em relação às inflorescências observou-se um crescimento até atingir máximo aos 94 DAT com valor estimado de 28,67 g planta $^{-1}$ (Figura 1). O acúmulo de massa seca nos frutos foi influenciado pelas épocas de amostragem. Com o início da frutificação houve um maior direcionamento de fotoassimilados para os frutos, sendo observado o 
Tabela 1 - Resumo da análise de variância das características acúmulo massa seca nas folhas (MSF), ramos (MSR), inflorescências (MSI), frutos (MSFR) e total (MST) de tomate 'SM-16' cultivado com cobertura ou não do solo com polipropileno preto. Baraúna/RN, UFERSA, 2010

\begin{tabular}{lccccc}
\hline \multirow{2}{*}{ FV } & \multicolumn{5}{c}{ Quadrado Médio (QM) } \\
\cline { 2 - 6 } & MSF & MSR & MSI & MSFR & MST \\
\hline Bloco & 2636,74 & 1982,06 & 85,29 & 2215,50 & 10762,28 \\
Cobertura do solo (C) & $679,38^{\text {N.S }}$ & $184,21^{\text {N.S }}$ & $23,62^{\text {N.S }}$ & $5570,67^{\text {N.S }}$ & $5268,40^{\text {N.S }}$ \\
Erro a & $843,28^{*}$ & 535,13 & 22,34 & 9604,42 & 11478,74 \\
Épocas (E) & $89886,55^{* *}$ & $23987,22^{* *}$ & $1051,49^{* *}$ & $195017,67^{* *}$ & $797668,63^{* *}$ \\
Cx E & $2026,51^{\text {N.S }}$ & $732,98^{\text {N.S }}$ & $21,25^{\text {N.S }}$ & $5602,60^{\text {N.S }}$ & $11886,58^{\text {N.S }}$ \\
Erro b & 3147,68 & 563,31 & 32,65 & 9384,28 & 22312,44 \\
CV 1 (\%) & 19,52 & 30,83 & 29,39 & 51,35 & 28,12 \\
CV 2 (\%) & 37,70 & 31,63 & 35,52 & 50,76 & 39,20 \\
\hline
\end{tabular}

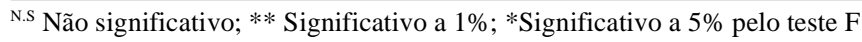

Tabela 2 - Resumo da análise de variância das características área foliar (AF), Razão de área foliar (RAF), Taxa de crescimento absoluto (TCA), Taxa de crescimento relativo (TCR) e Taxa assimilatória líquida (TAL) de tomate 'SM-16' cultivado com cobertura ou não do solo com polipropileno preto. Baraúna/RN, UFERSA, 2010

\begin{tabular}{lcclcl}
\hline \multirow{2}{*}{ FV } & \multicolumn{5}{c}{ Quadrado Médio (QM) } \\
\cline { 2 - 6 } & AF & RAF & \multicolumn{1}{c}{ TAL } & TCA & \multicolumn{1}{c}{ TCR } \\
\hline Bloco & 289570810,28 & 763,01 & 0,000000005416667 & 4,07 & 0,000011 \\
Cobertura do solo (C) & $24454547,83^{\text {N.S }}$ & $1338,08^{\text {N.S }}$ & $0,0000000006525^{\text {N.S }}$ & $18,72^{\text {N.S }}$ & $0,000011^{\text {N.S }}$ \\
Erro a & 79005214,54 & 140,92 & 0,000000001875 & 9,78 & 0,000027 \\
Épocas (E) & $6,73350183^{* *}$ & $24485,59^{* * *}$ & $0,000001^{* *}$ & $619,38^{\text {N.S }}$ & $0,056168^{* * *}$ \\
C x E & $34263727,80^{\text {N.S }}$ & $777,13^{\text {N.S }}$ & $0,0000000391964^{\text {N.S }}$ & $48,98^{\text {N.S }}$ & $0,000482^{\text {N.S }}$ \\
Erro b & 34263727,80 & 616,19 & 0,000000114479 & 304,13 & 0,000984 \\
CV 1 (\%) & 21,47 & 8,14 & 10,50 & 54,93 & 6,65 \\
CV 2 (\%) & 44,62 & 17,02 & 82,02 & 306,29 & 40,41 \\
\hline
\end{tabular}

N.S Não significativo; ** Significativo a $1 \%$; *Significativo a $5 \%$ pelo teste $\mathrm{F}$

Tabela 3 - Valores médios da massa seca de folhas (MSF), ramos (MSR), inflorescências (MSI), frutos (MSFR) e total (MST), ao longo do ciclo de tomate 'SM-16' cultivado com cobertura ou não do solo com polipropileno preto. Baraúna/RN, UFERSA, 2010

\begin{tabular}{lccccc}
\hline Cobertura do solo & MSF $\left(\mathrm{g}\right.$ planta ${ }^{-1)}$ & MSR $\left.(\mathrm{g} \mathrm{planta})^{-1}\right)$ & MSI $\left(\mathrm{g} \mathrm{planta} \mathrm{a}^{-1}\right)$ & MSFR $\left.(\mathrm{g} \mathrm{planta})^{-1}\right)$ & MST $\left(\mathrm{g} \mathrm{planta}^{-1}\right)$ \\
\hline Sem cobertura & $145,54 \mathrm{a}$ & $76,73 \mathrm{a}$ & $16,73 \mathrm{a}$ & $180,07 \mathrm{a}$ & $371,97 \mathrm{a}$ \\
TNT & $152,06 \mathrm{a}$ & $73,34 \mathrm{a}$ & $15,44 \mathrm{a}$ & $201,62 \mathrm{a}$ & $390,12 \mathrm{a}$ \\
Média Geral & 148,80 & 75,04 & 16,09 & 190,84 & 381,05 \\
\hline
\end{tabular}

Médias seguidas da mesma letra, na coluna, não diferem entre si, pelo Teste de Tukey, a 5\%

Tabela 4 - Valores médios de área foliar (AF), razão de área foliar (RAF), taxa assimilatória líquida (TAL), taxa de crescimento absoluto (TCA) e taxa de crescimento relativo (TCR) ao longo do ciclo de tomate 'SM-16' cultivado com cobertura ou não do solo com polipropileno preto. Baraúna/RN, UFERSA, 2010

\begin{tabular}{lccccc}
\hline Cobertura do solo & AF $\left(\mathrm{cm}^{2}\right.$ planta $\left.{ }^{-1}\right)$ & RAF $\left(\mathrm{cm}^{2} \mathrm{~g}^{-1}\right)$ & TAL $\left(\mathrm{g} \mathrm{cm}^{-2} \mathrm{dia}^{-1}\right)$ & TCA $\left(\mathrm{g} \mathrm{planta}\right.$ dia $\left.^{-1}\right)$ & $\left.\mathrm{TCR}^{(\mathrm{g} \mathrm{g}-1} \mathrm{dia}^{-1}\right)$ \\
\hline Sem cobertura & $40786,04 \mathrm{a}$ & $141,24 \mathrm{a}$ & $0,000409 \mathrm{a}$ & $5,15 \mathrm{a}$ & $0,0767 \mathrm{a}$ \\
TNT & $42022,33 \mathrm{a}$ & $150,39 \mathrm{a}$ & $0,000416 \mathrm{a}$ & $6,23 \mathrm{a}$ & $0,0785 \mathrm{a}$ \\
Média Geral & 41404,12 & 145,82 & 0,000413 & 5,69 & 0,0776 \\
\hline
\end{tabular}

Médias seguidas da mesma letra, na coluna, não diferem entre si, pelo Teste de Tukey, a 5\% 
crescimento acelerado na massa seca dos mesmos a partir dos 56 DAT atingindo o máximo aos 98 DAT (376,56 g planta $\left.^{-1}\right)$, (Figura 1).

Figura 1 - Acúmulo de massa seca de total, folhas, ramos, inflorescência e frutos de tomate 'SM-16', cultivado com e sem cobertura do solo com polipropileno preto. Baraúna/RN, UFERSA, 2010

- - $\hat{\mathrm{Y}}$ total $=717,377 /(1+\operatorname{EXP}(-0,111(\mathrm{X}-59,843))) \quad \mathrm{R}^{2}=0,98$

-..- $\hat{Y}$ folhas $=234,279 /(1+\operatorname{EXP}(-0,131(\mathrm{X}-48,027))) \quad \mathrm{R}^{2}=0,90$

$\hat{\mathrm{Y}}$ ramos $=124,385 /(1+\operatorname{EXP}(-0,126(\mathrm{X}-51,387))) \mathrm{R}^{2}=0,99$

$-\hat{\mathrm{Y}}$ infloresc. $=26,142 /(1+\operatorname{EXP}(-0,137(\mathrm{X}-58,646))) \mathrm{R}^{2}=0,98$

$-\hat{\mathrm{Y}}$ frutos $=336,608 /(1+\operatorname{EXP}(-0,179(\mathrm{X}-71,561))) \mathrm{R}^{2}=0,98$

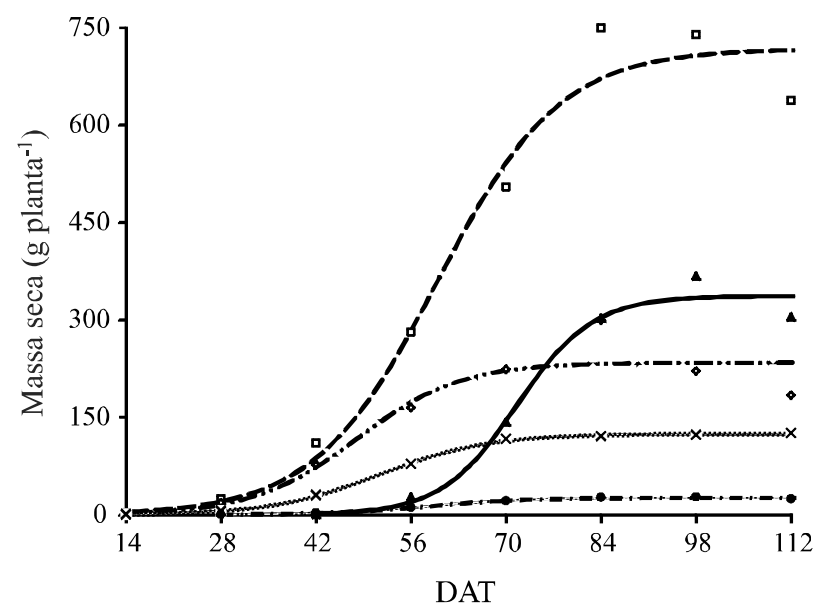

No início do ciclo aos 14 DAT, as folhas foram responsáveis pelo maior percentual de massa seca acumulada, com aproximadamente $77,96 \%$ se comportando como fonte-dreno, uma vez que são as responsáveis pela produção de fotoassimilados. Nesta mesma época os ramos se comportaram como dreno (Figura 2). A partir dos 28 DAT, com o início da fase reprodutiva e emissão das primeiras inflorescências, já foi possível perceber um deslocamento dos assimilados das folhas, que nesta época representam $75,51 \%$ da massa seca total, para os ramos $(23,68 \%)$ e inflorescências $(0,01 \%)$ (Figura 2). Com o início da frutificação, o direcionamento dos assimilados das folhas para os frutos ocorre de forma intensa, de modo que aos 56 DAT os frutos foram responsáveis por $9,55 \%$ de toda a massa seca e as folhas por $58,95 \%$. Ramos, inflorescências e frutos se comportam como dreno, entretanto os frutos foram o dreno preferencial da planta e chegaram ao final do ciclo com 47,77\%, enquanto as folhas representaram apenas $28,74 \%$, ramos $19,72 \%$ e inflorescências $3,77 \%$ da massa seca acumulada (Figura 2). Resultados semelhantes foram encontrados por Negreiros et al. (2010) que avaliando crescimento de tomate 'SM-16' cultivado sob diferentes coberturas de solo observou que no final do ciclo a planta acumulou em média 28,5; 14,8; 4,3 e 52,5\% de massa seca nas folhas, ramos, cachos florais e frutos, respectivamente. Fayad et al. (2001) também verificaram que os frutos foram o dreno preferencial da planta, tanto para o tomate EF-50, que ao final do ciclo, do total de massa seca produzida, $25 \%$ estavam presentem nas folhas, $5 \%$ no caule, $2 \%$ nos cachos florais e $68 \%$ nos frutos, como para a cv. Santa Clara, onde os frutos chegaram a acumular $51 \%$ do total da massa seca produzida pela planta, seguida por $33 \%$ nas folhas, $14 \%$ no caule e por último $2 \%$ nos cachos florais.

Figura 2 - Partição de assimilados de tomate 'SM-16', cultivado com e sem cobertura do solo com polipropileno preto. Baraúna/RN, UFERSA, 2010

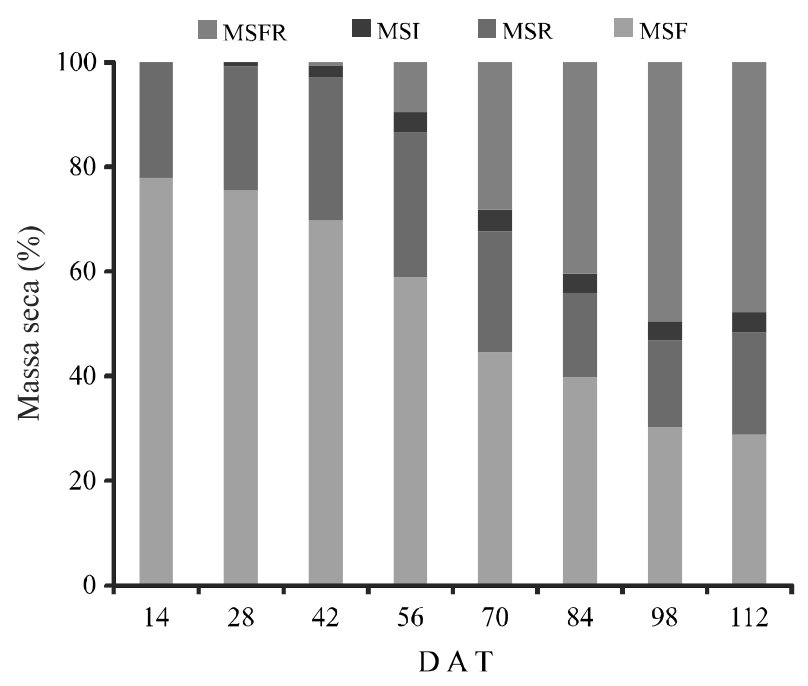

Em relação à área foliar observou-se um aumento até os 83 DAT, após esse período observa-se um decréscimo (Figura 3A). Lopes et al. (2009) observaram para a mesma cultivar que o aumento da área foliar ocorreu até os 70 DAT. Rodrigues et al. (2010) observavam que para a cultivar Mariana, quando comparados a outros materiais de cobertura de solo, o TNT apresentou máximo de área foliar, ocorrido aos 71 DAT. Fayad et al. (2001) verificaram comportamento semelhante para o híbrido EF-50, com o declínio na área foliar a partir dos 93 DAT; para a cv. Santa Clara observaram que o declínio ocorreu a partir dos 58 DAT. A razão de área foliar se comportou de forma decrescente ao longo do ciclo da cultura, obtendo o valor máximo aos 27 DAT com média de $201,5 \mathrm{~cm}^{2} \mathrm{~g}^{-1}$ e o valor mínimo aos 112 DAT com $60,33 \mathrm{~cm}^{2} \mathrm{~g}^{-1}$ (Figura 3B). O seu decréscimo indica que progressivamente a quantidade de assimilados destinados às folhas é diminuída, em função do desenvolvimento das 
estruturas de sustentação e reprodutivas em detrimento do investimento em área foliar. Lopes et al. (2011) verificaram comportamento linear decrescente durante o ciclo da cultura. Peluzio et al. (1999) afirmam que a RAF apresenta decréscimo com a ontogenia da planta. No cultivo do pimentão, Silva et al. (2010) verificaram que a RAF decresceu em função da idade da planta, resultado também descrito por Fontes, Dias e Silva. (2005).

Figura 3 - Área foliar (A), razão de área foliar (B) de plantas de tomate 'SM-16' cultivado sob diferentes coberturas de solo. Baraúna/RN, UFERSA, 2010
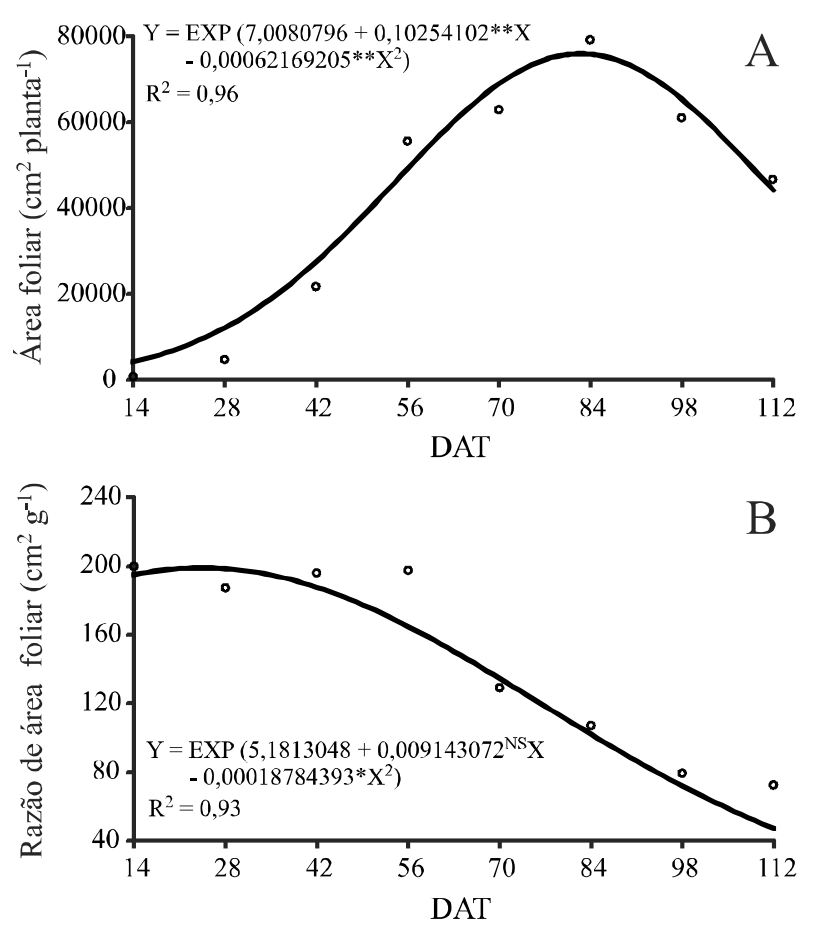

A taxa assimilatória líquida (TAL) também foi decrescente desde os 14 DAT até o final do período de avaliação, atingindo aos 112 DAT a média de $0,000100597 \mathrm{~g} \mathrm{~cm}^{-2} \mathrm{dia}^{-1}$ (Figura 4A). Com o crescimento da planta, inclusive da área foliar, iniciou-se um autosombreamento das folhas, o que levou à diminuição dos níveis de fotossíntese líquida, ou seja, redução na TAL. Lopes et al. (2011) observaram que a taxa assimilatória líquida aumentou até 28 DAT, decrescendo com a idade da planta. Avaliando o híbrido EF-50 Fayad et al. (2001) verificaram que a TAL declinou durante o ciclo da cultura. Peluzio et al. (1999) verificaram aumento gradativo até 69 DAT, com posterior decréscimo. As épocas de amostragem não apresentaram efeito significativo, pelo Teste F, para a taxa de crescimento absoluto, entretanto observou-se uma tendência de crescimento até 84 DAT com média de 17,48 g planta gia $^{-1}$ e posterior decréscimo, atingindo aos 112 DAT a média de -7,19 g planta $^{-1}$ dia $^{-1}$ (Figura 4B). Fayad et al. (2001) verificaram que a taxa de crescimento absoluto cresceu até os 45 DAT, decrescendo a partir desta época, para o tomate cv. Santa Clara, já no tomate EF-50, ocorreu crescimento até 75 DAT e posterior decréscimo, até o final do ciclo. De modo semelhante ao observado no presente trabalho. A taxa de crescimento relativo (TCR) decresceu a partir dos 14 DAT (0.2138993589 $\left.\mathrm{g} \mathrm{g}^{-1} \mathrm{dia}^{-1}\right)$ até o final do ciclo da cultura aos 112 DAT (-0.026110880 $\left.\mathrm{g} \mathrm{g}^{-1} \mathrm{dia}^{-1}\right)$ (Figura 4C). Decréscimos nos valores de TCR ao longo do ciclo são comuns para a maioria das espécies, inclusive para o tomate, estando relacionados aos decréscimos na taxa assimilatória líquida (TAL) e na razão de área foliar

Figura 4 - Taxa assimilatória líquida (A), taxa de crescimento absoluto (B), taxa de crescimento relativo (C) de plantas de tomate 'SM-16' cultivado sob diferentes coberturas de solo. Baraúna/RN, UFERSA, 2010


DAT 
(RAF). Fayad et al. (2001) verificaram que houve redução da TCR durante todo o ciclo da cultura, tanto para o tomate cv. Santa Clara, como para o híbrido EF-50. Em trabalho realizado com pimentão, Fontes, Dias e Silva (2005) afirmaram que a TCR decresceu durante todo o ciclo.

\section{CONCLUSÕES}

1. A cobertura de solo não influenciou o acúmulo de massa seca nas folhas, ramos, inflorescências, frutos e total, como também a área foliar, razão de área foliar, taxa assimilatória líquida, taxa de crescimento absoluto e taxa de crescimento relativo;

2. Os frutos se comportaram como dreno preferencial da planta, chegando ao final do ciclo com $47,77 \%$ do total da massa seca acumulada;

3. A área foliar, RAF e TCA atingiram valores máximos aos 83; 27 e 73 DAT, com médias de $75.835 \mathrm{~cm}^{2}$ planta $^{-1}$, $201,5 \mathrm{~cm}^{2} \mathrm{~g}^{-1}$ e $14,87 \mathrm{~g} \mathrm{planta}^{-1} \mathrm{dia}^{-1}$, respectivamente, enquanto a TCR e a TAL decresceram durante todo o período de avaliação.

\section{AGRADECIMENTOS}

Ao CNPq pelo apoio financeiro e à WG Fruticultura pelo apoio logístico.

\section{REFERÊNCIAS}

ALLEN, R. G. et al. Crop evapotranspiration: guidelines for computing crop water requirements. Rome: FAO, 1998. 279 p. (FAO, Irrigation and Drainage Paper, 56).

BENINCASA, M. M. P. Análise de crescimento de plantas: noções básicas. 2. ed. Jaboticabal: Funep, 2003. 41p.

CHAVES, S. W. P. et al. Rendimento de alface em função da cobertura do solo e freqüência de irrigação. Caatinga, v. 17, n. 1, p. 25-31, 2004.

DANTAS, M. S. M. et al. Rendimento e qualidade de frutos de melancia cultivada sob proteção de agrotêxtil combinado com mulching plástico. Horticultura Brasileira, v. 27, n. 2, p. S662-S667, 2009.

EMPRESA BRASILEIRA DE PESQUISA AGROPECUÁRIA. Centro Nacional de pesquisa do solo. Sistema brasileiro de classificação de solos. Rio de Janeiro: Serviço de produção de informação, 1999. 412 p.

ORGANIZAÇÃO DAS NAÇÕES UNIDAS PARA A AGRICULTURA E A ALIMENTAÇÃO. Production. Disponível em: < http://faostat.fao.org/site/339/default.aspx>. Acesso em: 27 nov. 2012.
FAYAD, J. A. et al. Crescimento e produção do tomateiro cultivado sob condições de campo e de ambiente protegido. Horticultura Brasileira, v. 19, n. 3, p. 232-237, 2001.

FERREIRA, D. F. Análises estatísticas por meio do Sisvar para Windows versão 4.0. In: REUNIÃO ANUAL DA REGIÃO BRASILEIRA DA SOCIEDADE INTERNACIONAL DE BIOMETRIA, 45, 2000. Anais... São Carlos: SIB, 2000. p. 255-258.

FONTES, P. C. R.; DIAS, E. N.; SILVA, D. J. H. Dinâmica do crescimento, distribuição de matéria seca e produção de pimentão em ambiente protegido. Horticultura Brasileira, v. 23, n. 1, p. 94-99, 2005.

INSTITUTO BRASILEIRO DE GEOGRAFIA E ESTATÍSTICA. Levantamento sistemático da produção agrícola. v. 25, n. 10, p. 1-84, 2012.

JANDEL SCIENTIFIC. Table Curve: curve fitting software. Corte Madera, CA: Jandel Scientific, 1991. 280 p.

KVET, J. et al. Methods of growth analysis. In: SESTAK, Z. J. C. JARVIS, P. G. (Ed.). Plant photosynthetic production; manual of methods. Haia: W. Junck, 1971. p. 343-391.

LAMONT JUNIOR, W. J. Plastic mulches for the production of vegetable crops. Hort Technology, v. 3, n. 1, p. 35-39, 1993.

LOPES, W. A. R. et al. Análise do crescimento de tomate 'SM16' cultivado sob diferentes coberturas de solo. Horticultura Brasileira, v. 29, n. 4, p. 554-561, 2011.

LOPES, W. A. R. et al. Crescimento de tomate SM-16 sob diferentes tipos de coberturas de solo. Horticultura Brasileira, v. 27, n. 2, S486-S491, 2009.

MEDEIROS, J. F. et al. Crescimento e produção do melão cultivado sob cobertura de solo e diferentes freqüências de irrigação. Revista Brasileira de Engenharia Agrícola e Ambiental, v. 10, n. 4, p. 792-797, 2006.

MEDEIROS, J. F. et al. Produção de melão Cantaloupe influenciado por coberturas do solo, agrotêxtil e lâminas de irrigação. Horticultura Brasileira v. 25, n. 4, p. 538-543, 2007.

MORAIS, E. R. C. et al. Crescimento e produtividade do meloeiro Goldex influenciado pela cobertura do solo. Scientia Agrária, v. 9, n. 2, p. 129-137, 2008.

NEGREIROS, M. Z. et al. Crescimento e desenvolvimento de tomate 'SM-16' cultivado sob diferentes coberturas de solo. Horticultura Brasileira, v. 28, n. 2, S1732-S1738, 2010.

PELUZIO, J. M. et al. Comportamento da fonte e do dreno em tomateiro após a poda apical acima do quarto cacho. Ciência e Agrotecnologia, v. 23, n. 3, p. 510-514, 1999.

QUEIROGA, R. C. F. et al. Utilização de diferentes materiais como cobertura morta do solo no cultivo do pimentão. Horticultura Brasileira, v. 20, n. 3, p. 416-418, 2002.

REGHIN, M. Y. et al. Produção de alface utilizando cobertura do solo e proteção de plantas. Scientia Agraria, v. 3, n.1/2, p. 69-77, 2002. 
RODRIGUES, G. O. S. et al. Crescimento de tomate 'Mariana' em função dos diferentes tipos de cobertura do solo. Horticultura Brasileira, v. 28, n. 2, S1883-S1890, 2010.

SEMINIS - produtos - tomate determinado - SM-16 Disponível em: <http://www.seminis.com.br/products/ tomate/sm_16.asp>. Acesso em: 6 jan. 2011.
SILVA, P. I. B. et al. Crescimento de pimentão em diferentes arranjos espaciais. Pesquisa Agropecuária Brasileira, v. 45, n. 02 , p. 132-139, 2010

YIN, X. et al. A flexible sigmoid function of the determinate growth. Annals of Botany, Oxford, England, v. 91, n. 3, p. 361-371, 2003. 